\title{
Simios, derechos y torceduras ${ }^{1}$
}

\author{
Simians, rights and sprains
}

\author{
Ana CRISTINA Ramírez BarReto \\ Instituto de Investigaciones Filosóficas, Universidad Michoacana de San Nicolás de Hidalgo, \\ México
}

RESUMEN. Comento las reacciones a la propuesta de que España apoye la Declaración del Proyecto Gran Simio. Sostengo que no hay unidad ni homogeneidad en las posiciones éticas y de filosofía política de quienes suscribimos dicha Declaración. Por otra parte, la evocación de otras movilizaciones emancipatorias no debe entenderse superficialmente, restringida a un uso retórico y sentimental, pues sí hay aspectos análogos en las formas de argumentación y contraargumentación sobre si estos sujetos (esclavos, mujeres $\mathrm{u}$ otros grandes simios) merecerían un trato distinto y por qué. Finalmente, sostengo que el concepto de humanidad, y las prerrogativas que como tal parece que le son naturales, se revela ya no como un dato contundente, luminoso e inobjetable sino como un problema filosófico y discursivo, abierto a la intervención humana.

Palabras clave: Proyecto Gran Simio, movilizaciones emancipatorias, humanidad.

Introducción: simios y simias, grandes $y$ no tanto, en el humanismo

Humanismo es una palabra densa, pesada, inobjetable; se deja caer en los argumentos como un marro sobre una nuez, para acabar con la discusión, para cerrar el día e irse a cenar. En nuestros días, la ambigüedad en la que subsiste el término
AbSTRACT. This paper comments the reactions to the proposal that Spain supports Great Ape Project Declaration. Those of us who subscribe this Declaration do not share the same ethical or political position. Also, the mention of other emancipatory struggles (slaves, women, indigenous people) must not be restricted to a rhetorical and sentimental use, because there are some analogous aspects, indeed. Finally, I sustain that the concept of humanity is no longer a self-evident fact, but a philosophical and discoursive problem, opened to the human intervention.

Key words: Great Ape Project, emancipatory struggles, humanity.

«humanista» no reduce su efectividad retórica ¿Se refiere a esa secularización del mundo que operó en la Europa renacentista y que - más o menos heréticamente- - descentró la figura de Dios poniendo al ser humano como referencia terrenal para los valores sociales, éticos, religiosos y epistemológicos? ¿O se refiere a la segunda revolcada del discurso providen- 
cialista, conservador, que machaca, ahora desde una antropología filosófico-teológica, el discurso de la «dignidad de la persona humana» $\mathrm{y}$ de su naturaleza como criatura hecha a imagen y semejanza de Dios? ¿O quizá se refiere a la humanidad como proyecto inacabado, orientado por un ideal moral: la bondad de carácter, la mansedumbre y el rechazo fundamental a la crueldad que eventualmente no puede verse como un rasgo ni distintivo ni único de la especie humana ${ }^{2}$ ?

Con esa misma ambigüedad y contundencia hemos convenido que las garantías jurídicas (o derechos fundamentales a la vida, a la libertad, a no ser violentado) son derechos para los miembros de la especie humana, desde el momento de la concepción de un nuevo individuo y hasta su muerte, de manera continua y homogénea. Esto puede transformarse a corto plazo, no precisamente para excluir humanos sino para considerar los intereses de otros animales. Una reciente iniciativa parlamentaria del Partido Socialista Español (2006) pide al Gobierno respaldar las demandas del llamado Proyecto Gran Simio, y pronunciarse contra la tortura, confinamiento y muerte de los simios antropoides («grandes simios» o miembros de la «familia» Hominidae): humanos, gorilas, chimpancés, bonobos y orangutanes.

El debate desatado ha puesto de relieve interesantes prejuicios, sobre los cuales versa este comentario con la siguiente estructura: en un primer apartado destaco lo equívoco del desliz que más escandaliza a quienes sienten que el humanismo peligra si España se adhiere a la Declaración de los Grandes Simios: el desliz consiste en que, a partir de una propuesta de atención y protección a otros simios, pasamos al lenguaje de los derechos jurídicos y, desde ahí, a la idea de que éstos son derechos humanos, sólo para humanos. En un segundo apartado sostengo que este desliz está vinculado a un argumento que sostiene que la iniciativa de apoyo a la Declaración del Proyecto Gran Simio es contraria a las buenas costumbres de la teoría política, específicamente cuando se hacen analogías con la lucha por los derechos civiles de los esclavos afroamericanos y las mujeres. En un tercer apartado exploro las razones que ha tenido el alto clero español para rechazar con desdén la iniciativa. En un cuarto apartado me detengo en el argumento que se preocupa por cómo la aprobación de la iniciativa puede afectar la contundencia de los «derechos humanos», devaluándolos $\mathrm{y}$, finalmente, dejando en el desamparo a los humanos que requieren su protección.

Concluyo enfatizando que todo este abanico de objeciones tiene por raíz común la reacción a un efecto secundario de las demandas del Proyecto Gran Simio: que el concepto de humanidad (y las prerrogativas que como tal parece que le son naturales) se revela ya no como un dato contundente, luminoso e inobjetable sino como un problema filosófico $y$ discursivo, abierto a la peluda intervención de estos artificiosos simios que somos los humanos, incluyendo a los más declaradamente humanistas.

\section{Ni tan derechos ni tan humanos}

El Proyecto Gran Simio (PGS) es movimiento amplio y heterogéneo, un libro colectivo y una Declaración propuesta para que la suscriba e impulse la Organización de las Naciones Unidas (ONU). Muy lejos de estar sustentado en «una filosofía» (sea esto lo que quiera que signifique), las personas adscritas al PGS y a su Declaración justifican su postura en razones muy diversas e incluso contradictorias (Ramírez, 1999: 192-194). Hay quienes proponen que, con miras a su 
protección y tutela, se les otorgue humanidad honoris causa a los no humanos, pero también hay quienes se esfuerzan porque se protejan los grandes simios y su hábitat como se protegen los centros históricos de las ciudades, por ser patrimonio de la humanidad, lo cual no es ni remotamente igualarlos con humanos (Ramírez, 2004:164), y también hay quienes suscriben el PGS apelando a la condición rica y variada de la existencia de los grandes simios, sin homologar diferencias ni declarar identidades metafísicas. Por tanto, es completamente falso que detrás de PGS esté sólo el escandaloso-utilitarismo-pro-infanticidio de Peter Singer (cfr. Marcos, 2006: 63-67) o sólo el sentimental-y-dudosamente-científicomaternalismo-colonialista de Jane Goodall.

Si bien el subtítulo del libro PGS («La equidad más allá de la humanidad») hace pensar que se trata de humanizar a los simios no humanos, tras la revisión cuidadosa de las diversas propuestas vemos que no es así. El texto mismo de la Declaración no se circunscribe al lenguaje de los «derechos». La transcribo y enfatizo la mención a la vía de los «principios morales», que es diferente a la de los derechos:

Exigimos que la comunidad de los iguales se haga extensiva a todos los grandes simios: los seres humanos, los chimpancés, los gorilas y los orangutanes.

La «comunidad de los iguales» es una comunidad moral dentro de la cual aceptamos que determinados principios morales o derechos fundamentales, que se puedan hacer valer ante la ley, rijan nuestras relaciones mutuas. Entre estos principios o derechos figuran los siguientes:

1) El derecho a la vida. Debe protegerse la vida de los miembros de la comunidad de los iguales. No puede darse muerte a los miembros de la comunidad de los iguales, excepto en circunstancias que se definan muy estrictamente, por ejemplo: en defensa propia.
2) La protección de la libertad individual. No puede privarse arbitrariamente de su libertad a los miembros de la comunidad de los iguales. Si se les aprisiona sin que medie un proceso legal, tienen el derecho a ser liberados de manera inmediata. La detención de quienes no hayan sido condenados por un delito, o de quienes carezcan de responsabilidad penal, sólo se permitirá cuando pueda demostrarse que es por su propio bien, o que resulta necesaria para proteger al público de un miembro de la comunidad que claramente pueda constituir un peligro para otros si está en libertad. En tales casos, los miembros de la comunidad de los iguales deben tener el derecho a apelar ante un tribunal de justicia, bien directamente o, si carecieren de la capacidad necesaria, mediante un abogado que los represente.

3) La prohibición de la tortura. Se considera tortura, y por tanto es moralmente condenable, infligir dolor grave, de manera deliberada, a un miembro de la comunidad de los iguales, ya sea sin ningún motivo o en supuesto beneficio de otros ${ }^{3}$.

Entre el reconocimiento de derechos y la decisión de otorgar garantías legales por principios morales media una enorme diferencia, casi la misma que entre el iusnaturalismo y el iuspositivismo, al igual que las relaciones antagónicas y complejas entre estas posiciones. Mientras que el iusnaturalismo apuesta por el «descubrimiento» de una naturaleza (humana hasta lo ahora planteado) ya dada que debe ser reconocida independientemente de las normas positivamente asentadas, el segundo prescinde de la metafísica noción de derecho natural fundado en la naturaleza humana, y hace que el derecho emane de la voluntad social e históricamente circunscrita (Beuchot y Saldaña, 2000).

Pues bien, las posiciones enfrentadas de quienes suscriben el PGS (que por lo demás pueden ser tan contrastantes como el iusnaturalismo y el iuspositivismo) me parece que convergen en la siguiente línea general: hay un prejuicio especista 4 
que se mueve en una irreflexiva y ambigua actitud hacia los otros grandes simios: son los sujetos/objetos preferidos de la experimentación biomédica avanzada, la actuación circense y el encierro en zoológicos justamente por ser antropoides, «lo más cercano» a la forma humana $\mathrm{y}$, sin embargo, con ellos se permiten prácticas proscritas para humanos, porque se les supone animales con el mismo estatus instrumentalizable que cualesquiera otros.

Entonces, no es ni inmediato ni general que la Declaración del PGS pida derechos humanos para animales no humanos, cuando lo que solicita expresamente es que los Estados miembros de la Organización de las Naciones Unidas acepten el reforzamiento de la consideración moral para los simios antropoides, donde también estamos los «miembros» de la «especie» humana, no como una caída, desgracia o reducción que afecta más a los «negros» que a los «blancos», $1^{5} \operatorname{sino}$ como nuestra única, heterogénea e insuperable condición de posibilidad de existencia.

\section{Contraria a las buenas costumbres de la teoría política}

Sin duda resulta inquietante que, al plantear los antecedentes y perspectivas del Proyecto Gran Simio, se mencionen las luchas por la abolición de la esclavitud y por la emancipación femenina. A los humanos tomados como base de la analogía suele preocuparles la comparación: después de tanto esfuerzo por reivindicar ante los varones blancos su igual dignidad humana y su derecho al señorío de sí ¿nuevamente se les equipara a los animales, a la condición de naturaleza? ¿No debería detenerse el lenguaje de los derechos en humanos de ambos sexos, de cualquier condición sociocultural y económica, pero sólo humanos? Si nos per- mitimos pensar en derechos de otros animales que no cumplan con esta elemental condición de la especie ¿acaso dejarán de ser convincentes las razones para la emancipación de los esclavos y las mujeres? Si la noción de dignidad y vidaque-merezca-vivirse se extiende más allá de la multifacética especie humana ¿se revelará la inconsistencia de no discriminar y no restringir las esferas de oportunidades para una vida-en-florecimiento en función de diferencias supuestamente naturales, como el color de la piel o el sexo genital?

Por ejemplo, Alfredo Marcos Martínez (2007) considera que el PGS utiliza la analogía con las empresas políticas - abolición de esclavitud, liberación femenina - sólo como una apoyatura meramente retórica y emotiva, sin bases ni científicas ni filosóficas. Por el contrario, yo encuentro que incluso esta depreciación que él hace del argumento crítico cae en la lógica histórica de esas luchas políticas. No se trata de una analogía forzada, sino de un camino ya recorrido y visto en sus principales estaciones: a) la fe en que la diferencia de naturaleza implica una jerarquía moral; b) la fe en que, si esto no es así, es a ellos (esclavos, mujeres, animales) a quienes les corresponde probar contundentemente que pueden realizar los actos que todos sabemos que son incapaces de realizar (actos de civilización, cultura y auténtica vida espiritual, es decir, humana); y c) la fe en que, si esto no es así y se demandan cambios jurídicos y culturales, debemos prevenirnos para una catástrofe, pues «el cielo puede caerse en pedazos»».

Erróneamente se interpreta que el dato sobre la cercanía filogenética de los antropoides per se tiene implicaciones éticas y jurídicas. Se mantiene la diferencia «de especie» (como sea que este polémico término se entienda, ver Cela, 2000), como se mantiene la del tono de 
piel y el sexo genital. Lo que se objeta cuando se documentan estos datos recurriendo a las herramientas de la genética, la etnografía, la psicología, la lingüística... es que la diferencia, tomada seriamente, no es tanto «de naturaleza» (metafísica) como de variaciones aterrizadas y en contexto, que los antropoides son capaces de una vida rica social y emocionalmente interesante para ellos; que no verla no ha sido tanto una limitación suya sino una deformación de nuestra manera de acceder a ella ${ }^{6}$.

Hace poco, durante un examen profesional, tuve la oportunidad de ver un ejemplo claro de la segunda estación de este recorrido histórico y político. La tesista declaraba la incapacidad de los otros animales (todos y cualesquiera) para la vida expresiva. ¿Por qué son esencialmente incapaces de ello? —pregunté yo- - Su respuesta fue la circularidad familiar a quien estudia la historia del feminismo: «No nos han demostrado tener vida expresiva». La carga de la prueba la tiene quien ha sido ya previamente invalidado para probar nada. En México, el derecho al voto femenino se negó, primero, en la «evidencia» de que a las mujeres realmente no les interesaba la vida política, por eso no estaban movilizadas para conseguirlo; luego, cuando la movilización fue innegable, se objetó que si bien algunas mujeres demostraban tener conciencia política y quizá estuvieran en condiciones para ejercer satisfactoriamente los derechos políticos, «no [se] funda la conclusión de que éstos deban concederse a la mujer como clase. La dificultad de hacer la selección autoriza la negativa» (Dictamen del Congreso, 1917, en Rascón, 1979). Dos décadas más tarde, en 1937, el derecho político al voto ya no se negaba en función de que fuera difícil seleccionar a las mujeres excepcionales que se lo merecían de entre la masa de incapaces, sino porque el cielo podía caerse: «el día que vengan a la cámara mujeres diputadas ¡nos enviarán a nosotros a realizar las labores del hogar!» - declaraban los senadores que todavía en 1937 dictaminaron en contra de los derechos políticos de las mujeres (Rascón, 1979) — La analogía no es forzada ni meramente retórica. Hay preocupación por el trauma que afectaría el orden establecido si propuestas como la del PGS nos obligan — ¡nuevamente! — a revisar los «conceptos básicos como el de sujeto de derechos o el de tutela» (Marcos, 2007: 68). Todavía peor, se teme que por una suerte de «contaminación animal» o zoonosis, el apoyo de España a la Declaración de los Grandes Simios implique debilitar toda «declaración de derechos [humanos]» como instrumento político con alguna autoridad moral (Marcos, 2007: 68).

La expresión «modificar una ley sin que el cielo se venga abajo» está directamente tomada de los incipientes pasos abolicionistas en Inglaterra, tan incipientes que realmente no se plantearon ser el inicio de la abolición de la esclavitud. El fallo en el caso Somerset $v$. Stewart (Inglaterra, 1772) sentó un precedente legal al liberar a un esclavo apoyado en diversas fuentes extralegales «sin que el cielo se viniera abajo». Realmente, sin siquiera atacar la esclavitud en general de manera radical, pues técnicamente el fallo del juez simplemente descargó al esclavo (en Inglaterra) de la obligación de irse con su amo (colono en América) a donde él no quería (Waldau, 2001: 78-88 y 106).

Desde luego, Aministía Internacional puede declararse desbordada si se le llega a cargar con la tarea de velar no sólo por simios humanos, como hasta ahora lo ha hecho, sino también por los simios no humanos ${ }^{7}$. Cerrar Guantánamo, parar las piedras y el ácido contra mujeres en Medio Oriente y la India, denunciar la tortu- 
ra y la violación como prácticas de guerra... son tareas ya abrumadoras. Pero también hemos aprendido de las luchas por los derechos cívicos y políticos que ninguno de los grandes problemas de nuestra historia reciente ha esperado a que los otros estuviesen resueltos para aparecer en escena y exigir atención. Lejos de un esquema basado en el modelo de una escalera - primero un peldaño y luego otro- estaríamos enfrentando algo más cercano a un fluido viscoso. No es que tengamos que resolver primero todos los problemas concernientes a la clase social para luego lograr la equidad de género, como pidieron los socialistas a las feministas en la primera mitad del siglo XX. La Declaración sobre los Grandes Simios no pretende postergar o devaluar los problemas humanos. Pareciera dejarlos intocados y, sin embargo, se trata de una gota que, cayendo sobre un fluido aparentemente inmóvil, provoca una última onda que ha rebotado contra los límites y se refracta intensificando los otros movimientos abolicionistas, emancipatorios o igualitarios —en todo caso, críticos.

\section{Contraria a la ley natural, fundada en la recta razón}

Algunas expresiones del alto clero español a propósito de la propuesta de apoyar la Declaración del PGS hacen patente el fondo de la disputa ideológica: la sola posibilidad de llegar a aceptar, en general y vagamente, las diferentes razones que se esgrimen a favor de la Declaración, es ya un atentado hacia la cosmovisión que mantiene cada cosa en su lugar, una expresión más de los tiempos de alarma en que vivimos.

A finales de 2006 la Conferencia Episcopal Española (CEE) dio a conocer su documento Orientaciones morales ante la situación actual de España. Ahí se alerta contra «el desarrollo alarmante del laicismo en nuestra sociedad», la nue- va ola de Ilustración que atenta contra el sentido de ubicación de las personas: su familia, su comunidad religiosa, su puesto en el mundo y ante su Creador. El documento se ocupa de «las leyes y declaraciones contrarias a la ley natural, que deterioran el bien moral de la sociedad», explícitamente menciona la separación de la definición de matrimonio de la referencia a la diferencia entre «el varón y la mujer», pero se aplicaría también a la demanda de abrir otra dimensión de consideración moral hacia los otros simios, pues, más aún que la posibilidad del matrimonio homosexual, las imaginerías en torno al PGS ponen en cuestión las nociones consagradas de «familia», «persona» y «moral». Se trata de actos declarados contra-natura, como el amor que sin sentido de pecado se declaran dos seres humanos (del «mismo» sexo), o la duda razonable sobre la inconciencia y falta de «espíritu» de otros simios antropoides distintos al humano. En la medida en que la posición a favor de los cambios de valoración se sustenta en el laicismo y la crítica al dogmatismo religioso y su idea de esencia humana, la posición conservadora pretende imputar a sus rivales la responsabilidad de un daño moral, cultural e histórico:

... para nosotros es claro que todo lo que sea introducir ideas y costumbres contrarias a la ley natural, fundada en la recta razón y en el patrimonio espiritual y moral históricamente acumulado por las sociedades, debilita los fundamentos de la justicia y deteriora la vida de las personas y de la sociedad entera (CEE, 2006, punto 17).

\section{Contraria a la esencia de los derechos humanos}

Así, según el arzobispo de Pamplona y Tudela, Fernando Sebastián, no se puede proteger para los monos (no humanos) lo que no está garantizado para embriones o fetos (humanos). En su perspectiva, hu- 
manidad y valor se han fundido en un sólo paquete, el cual queda bien delimitado, cerrado sobre sí. Humanidad y valor forman un solo quiste, una sola entidad regulada por la «ley natural fundada en la recta razón».

Las torcerduras a esta rectitud tratan de hacerse ver o bien como ridiculeces o como señales de perdición. Mover a risa: pedir derechos humanos para los simios «es como pedir derechos taurinos para los humanos» (arzobispo Sebastián en $E l$ Mundo, 24/04/2006) ${ }^{8}$; Mover al miedo: el mundo se volverá «culturalmente extraño y hostil» (CEE, 2006, punto 16).

De manera descriptiva: un representante político de un segmento de la población española, en pleno uso de sus facultades y apoyado en argumentos aparentemente sensatos, hace una petición a su Parlamento. Esta petición da a otro segmento de la población la impresión de ser descabellada, finalmente no por lo que pide sino por las razones por las que lo pide. Pueden dictarse leyes que tutelen el bienestar animal, que prohíban prácticas crueles y que protejan el nicho ecológico, pero no deben sustentarse estas acciones en razones que pongan en duda el puesto de cada cual en el cosmos. Cuando se protege la buena vida de un humano, decimos que es porque tiene derechos (humanos), de persona, ${ }^{9}$ lo cual parece claro y evidente; cuando se llegue a proteger la buena vida de otro animal, habrá que decir que no es porque tenga derechos o porque su vida sea tan valiosa para sí y los suyos como la de cualquier otro sintiente en su comunidad, lo cual nos compromete moralmente a cuidarla, sino porque es una norma del derecho positivo actual y ya. Basta de preguntas. Especialmente, basta de preguntarse ¿por qué nos parece valioso el bienestar?, ¿tiene que ser sólo humano?, ¿cómo podemos concebir el bienestar que sea única y exclusivamente humano?, ¿qué hay en el dolor y la muerte que nos parece intolerable, así en unos simios como en otros?

La filosofía en general, y la de los derechos humanos en particular, no pueden renunciar a formularse estas preguntas $\mathrm{y}$ ser consecuentes con sus luces y sus sombras. Es posible que la fundamentación más sólida de los «derechos humanos» no consista en que son derechos naturales de los miembros de una especie biológica identificable a primera vista.

\section{Conclusión}

Quizá lo mejor que le pueda pasar al planeta y a las queer families de las enredaderas filogenéticas que lo habitan (Haraway, 2003) es que el humanismo sea atemperado con una necesaria crítica, la cual algunos llaman poshumanista (Badmington, 2000; Braidotti, 2006) y que realmente no es tan reciente. La han formulado quienes combatieron la idea de que hay una esencia humana y que algunas personas viven conforme a ésta gracias a que los credos religiosos imperantes, los partidos políticos o los médicos han descubierto cuál es y han tratado de curar la que no es.

Cuando el término humanismo deja de ser absolutamente convincente y se permite acompañarlo de la crítica, pasa a verse desde otro ángulo el asunto de si lo que pide la Declaración del PGS son derechos humanos para otros simios o una práctica de relación responsable y atenta a lo que está ocurriendo, qué peligra y cómo se ponen en juego los necesarios contrapesos de valor.

No me inclino por la humanización de los otros simios antropoides, tampoco por su patrimonialización (otra estrategia para protegerlos en su habitat, ver Ramírez, 2004:164) ni mucho menos por su mascotización - disculpen los barbarismos-. Tanto adherentes al PGS como sus detractores han representado a los otros simios como humanos, como patri- 
monio de la humanidad o como nuestras mascotas. Sin embargo, lo que me resulta del todo alentador es que estas posiciones se estén discutiendo y se estén presentando sus supuestos al escrutinio público. Que la gente esté pensando cotidianamente cosas relativamente impensables antes, formulando preguntas, reflexionando sobre qué y quién define a un animal, una danza, un canto, una herramienta (¿cuentan como herramientas las varas para sacar termitas, las esponjas de hojas, la piedra y el palo para cascar nueces, si los manipula un simio no humano por haber aprendido a hacerlo?), qué es la conciencia, la responsabilidad, el neocolonialismo, la historia, la familia $y$ la-vida-que-merece-vivirse...

En suma, la ligereza con que se ha colocado la etiqueta de derechos humanos a la Declaración del PGS es para mí un mal menor que no resta emoción y entusiasmo al momento actual.

\section{BIBLIOGRAFÍA}

Badmington, Neil, 2000: Posthumanism, Houndmills, Basingstoke, Hampshire/New York: Palgrave.

Beuchot, Mauricio y Javier Saldaña, 2000: Derechos humanos y naturaleza humana, México: UNAM.

Braidotti, Rosi, 2006: Posthuman, All Too Human Towards a New Process Ontology. Theory, Culture \& Society, 23: 197-208.

Conferencia Episcopal Española (CEE), 2006: Orientaciones morales ante la situación actual de España, Madrid: Arquidiócesis de Madrid. En línea: http://www.archimadrid.es/archivo/cee/ Instru Pastoral/Asam plena_LXXXVIII/ OrientacionesSituacionActual.htm\# ftnref3 (acceso 4/05/2007).

Cela-Conde, Camilo et al., 2000: Grupo internacional de trabajo sobre la siste- mática de la paleontología humana. Declaraciones resumen con los resultados de las discusiones en sistemática de la humanidad en Coloquio Internacional sobre Sistemática Humana, Palma de Mallorca, España.

Gómez, Juan Carlos, Denise L. Herzing, Joyce H. Poole, John R. Searle, William O. Stephens, Michael Tooley, and Thomas I. White, 1998: Etica \& Animali, Special issue devoted to Nonhuman Personhood.

Haraway, Donna Jeanne, 2003: The companion species manifesto: dogs, people, and significant otherness, Chicago: Prickly Paradigm Press.

Herder, Johann Gottfried (1784-1791) 1959: Ideas para una filosofía de la historia de la humanidad. Trad. J. Rovira Armengol. Bs. As.: Losada.

Marcos Martínez, Alfredo, 2007: Política animal. El proyecto gran simio y los fundamentos filosóficos de la biopolítica. Revista latinoamericana de bioética, 7: 60-75.

Marks, Jonathan, 2006: Save the Apes From the Ape Rights Activists! Anthropology News, 47: 4-5.

Mosterín, Jesús, 1993: Filosofía de la cultura, Madrid: Alianza Editorial.

Ongay de Felipe, Íñigo, 2007: El Proyecto Gran Simio desde el materialismo filosófico. Intervención en la lectura y defensa de su tesis doctoral, dirigida por Gustavo Bueno Sánchez, celebrada en la Universidad de Oviedo el 11 de junio de 2007. El Catoblepas. Revista crítica del presente, 64: 1-10.

Pérez Tapias, José Antonio, 1995: Filosofía y crítica de la cultura, Madrid: Trotta.

Ramírez Barreto, Ana Cristina, 1999: Y cuando parecía que habíamos llegado al non plus ultra... Reseña de Cavalieri y Singer, El Proyecto Gran Simio. Trotta, Madrid, 1998. Ludus Vitalis. 
Revista de Filosofía de las Ciencias de la Vida, 7, 12: 189-197.

Ramírez Barreto, Ana Cristina, 2004: Salvajes, discapacitados y (otros) grandes simios. Aspectos antropológicos de la preocupación por los acercamientos, pp. 163-173 en Ética ecológica. Propuestas para una reorientación, J. Riechmann (ed.). Montevideo: Nordan. Rascón, María Antonieta, 1979: La mujer y la lucha social en la historia de México. Cuadernos Agrarios 9.
Sabater i Pi, Jordi (1978), 1992: El chimpancé y los orígenes de la cultura. Barcelona: Anthropos.

Staff, 2006: PSOE avala PGS, AI-España y Arzobispo lo rechazan. El mundo, Madrid, España. 24/04/2006. En línea: http://www.elmundo.es/elmundo/2006/ 04/24/sociedad/1145890969.html

Waldau, Paul, 2001: Will the Heavens Fall? De-Radicalizing the PrecedentBreaking Decision. Animal Law 7: 75-118.
1 Una traducción al alemán de este texto en Leitner, Claudia. Über die Grenzen des natürlichen Lebens: Inszenierungsformen des Mensh-Tier-Maschine Verhältnisses in der IberoRomania. Viena, Editorial LIT, 2008.

2 Humanität de J.G. Herder: «... Los animales más pacíficos y, valga la expresión, los más humanos, viven de las plantas...», Herder, 1784:119 (énfasis mío).

3 We demand the extension of the community of equals to include all great apes: human beings, chimpanzees, bonobos, gorillas and orang-utans. The community of equals is the moral community within which we accept certain basic moral principles or rights as governing our relations with each other and enforceable at law. Among these principles or rights are the following:

1. The Right to Life

The lives of members of the community of equals are to be protected. Members of the community of equals may not be killed except in very strictly defined circumstances, for example, self-defense.

2. The Protection of Individual Liberty

Members of the community of equals are not to be arbitrarily deprived of their liberty; if they should be imprisoned without due legal process, they have the right to immediate release. The detention of those who have not been convicted of any crime, or of those who are not criminally liable, should be allowed only where it can be shown to be for their own good, or necessary to protect the public from a member of the community who would clearly be a danger to others if at liberty. In such cases, members of the community of equals must have the right to appeal, either directly or, if they lack the relevant capacity, through an advocate, to a judicial tribunal.

3. The Prohibition of Torture

The deliberate infliction of severe pain on a member of the community of equals, either want only or for an alleged benefit to others, is regarded as torture, and is wrong.

Tomados de http://www.proyectogransimio.org/ declaracion.php y http://www.greatapeproject.org/declaration.php; énfasis míos.

${ }^{4}$ Digo especista y no especieísta porque sigo la ortografía que dice sexista (y no sexoísta) del prejuicio basado en la diferencia de sexo; racista (y no razaísta) del prejuicio basado en la diferencia de raza.

5 Cfr. Ongay de Felipe (2006), quien finaliza su artículo preguntando: «ipuede quedar (...) alguna duda sobre el hecho de que con el mismo movimiento en el que se "homologa" a los simios con los negros, se está en el fondo, reduciendo a los propios negros a la condición de simios?».

${ }^{6}$ Como escribió José Antonio Pérez Tapias pretendiendo refutar a Jesús Mosterín (1993), a Jordi Sabater Pi (1992) y, en general, a quienes se atreven a problematizar el monopolio de la «cultura» (como información socialmente transmitida) para la especie humana: "Mas aquí no se trata de una diferencia de cantidad, sino cualitativa, lo cual se hace ostensible poniéndose al final del proceso y mirando retrospectivamente: los chimpancés siguen haciendo lo mismo que hace miles de años; no hace falta insistir mucho en que no es el caso del hombre» (Pérez Tapias 1995:157). Esto lo escribe desde la distorsión que provoca sentarse ante la isla del chimpancé del zoológico $\mathrm{y}$, luego de algunas horas, declarar que lleva miles de años haciendo lo mismo (por eso está adentro de la jaula, y el humano afuera). Hace falta atender al estudio paciente, en su habitat o en otras condiciones bien observadas, que algunos investigadores se han permitido suponiendo que lo que hacen los otros simios es relevante -independientemente de si es mucho o poco comparado con la dorada «historia universal» de la humanidad-. 
7 Según El Mundo (Madrid, 24/04/2006), Delia Padrón, nueva presidenta de Amnistía Internacional España, «mostró su "sorpresa" por que se luche por lograr los "derechos humanos" de los simios "cuando, hoy por hoy, no se les reconocen a muchas personas"»».

8 Otro caso es el de Jonathan Marks (2006: 4), quien con toda seriedad pide que salven a los simios de los activistas que defienden sus derechos, pues con tanta restricción legal y moral ya los criaderos no surten chimpancés a los laboratorios estadounidenses como lo hacían en los buenos tiempos. Al cuestionar el sentido del PGS y reclamar que mejor debería pro- tegerse el hábitat natural de los grandes simios, Marks omite que es gracias al PGS que existe la Declaración de Kinshasa para la Sobrevivencia de los Grandes Simios (Great Apes Survival Project, GRASP), avalada por el Programa de Naciones Unidas para el Medio Ambiente (UNEP).

9 Por otra parte, no hay nada en el concepto de persona que lo haga sinónimo de «humano de la moderna especie Homo sapiens, uniformemente, desde la fecundación del óvulo por el espermatozoide y hasta su muerte», como el sentido común lo entiende ahora (Gómez, et al., 1998). 